ISPRS Annals of the Photogrammetry, Remote Sensing and Spatial Information Sciences, Volume IV-4/W4, 2017

4th International GeoAdvances Workshop, 14-15 October 2017, Safranbolu, Karabuk, Turkey

\title{
MODELLING PARTICIPATORY GEOGRAPHIC INFORMATION SYSTEM FOR CUSTOMARY LAND CONFLICT RESOLUTION
}

\author{
E. A. Gyamera ${ }^{1, *}$, A. Arko-Adjei², E. E. Duncan ${ }^{3}$, and J. S. Y. Kuma ${ }^{3}$ \\ ${ }^{1}$ Department of Soil Science, School of Agriculture, University of Cape Coast, Cape Coast. Ghana. \\ gyamengineering@yahoo.com \\ ${ }^{2}$.Department of Geomatic Engineering, Kwame Nkrumah University of Science and Technology, Kumasi, Ghana. \\ arkoajei@hotmail.com \\ ${ }^{3}$ Faculty of Mineral Resource Technology, University of Mines \& Technology, Tarkwa. Ghana. \\ eeduncan@umat.edu.gh,js.kuma@umat.edu.gh \\ Tel. +23324 4521145; Fax. +233332132709
}

KEY WORDS: Participatory GIS, Customary, Land, Conflict Resolution

\begin{abstract}
Since land contributes to about $73 \%$ of most countries Gross Domestic Product (GDP), attention on land rights have tremendously increased globally. Conflicts over land have therefore become part of the major problems associated with land administration. However, the conventional mechanisms for land conflict resolution do not provide satisfactory result to disputants due to various factors. This study sought to develop a Framework of using Participatory Geographic Information System (PGIS) for customary land conflict resolution. The framework was modelled using Unified Modelling Language (UML). The PGIS framework, called butterfly model, consists of three units namely, Social Unit (SU), Technical Unit (TU) and Decision Making Unit (DMU). The name butterfly model for land conflict resolution was adopted for the framework based on its features and properties. The framework has therefore been recommended to be adopted for land conflict resolution in customary areas.
\end{abstract}

\section{INTRODUCTION}

Conflict is seen to be a natural and integral part of the daily lives of mankind. It can occur in families, at work with colleagues or in negotiations between governments etc. At every point in human live, conflict pervades relationships (Margenthan, 1973). The paradox of conflict is that it is both the force that can tear relationships apart and the force that binds them together. This dual nature of conflict makes it an important concept to study and understand (Adetula, 2006).

Conflict is an inevitable and necessary feature of domestic and international relations (Lund, 2003). The underlying problem being faced by relationships both local and international is not about the occurrence or elimination of conflict, but how to effectively address or deal with conflict when it arises. Conflict can be managed negatively through avoidance at one extreme and the use or threat of force at the other. Alternatively, conflict can be managed positively through negotiation, joint problem solving and consensus building. These options help build and sustain constructive bi- and multi-lateral relations.

The aims for the development of the PGIS framework is to assess whether local people's experiences can be spatially modeled and introduced into land conflict resolution. It also seek to find out whether local knowledge can improve the spatial representation of processes by which land conflicts can be resolved and also supports government agencies and local authorities to release spatial indigenous information. It will further enquire whether participative approach provide communities with an easy to replicate method for working in partnership with other communities, and also further monitor the evolution of the conflicts within the communities.

\section{PARTICIPATORY GEOGRAPHICAL INFORMATION SYSTEMS}

Lamptey, (2009) expresses Participatory Geographic Information Systems (PGIS) as an umbrella term that depict the community application of a diverse range of Geographic Information Technologies and Systems (GITS). PGIS practice is based on using geo-spatial information management tools to represent peoples' local spatial knowledge in the virtual or physical, 2 or 3 dimensional maps used as interactive vehicles for spatial planning, discussion, information exchange, analysis, support (adding authority to local knowledge and community confidence) in advocacy, decision making and action-taking (Pascal, 2003). Many tools and approaches can be used, e.g. ephemeral maps (drawn on the ground, in sand, etc.) and sketch maps (including drawing mental maps); scale mapping (overlay drawing of spatial information onto existing topographic base maps), and similarly adding spatial information via overlays onto aerial photographs; satellite imagery; community surveying of new information using global positioning systems (GPS); incorporating this spatial information into GIS format; dynamic and web-based

* Corresponding author 
mapping; participatory 3-D models (P3DM); photography and video (Mandara, 2007).

Recent years have witnessed a burgeoning of applications of GIS which grant legitimacy to indigenous geographical knowledge as well as to 'official' spatial data. By incorporating various forms of community participation, these new Geographical Information Systems as 'Participatory GIS' (PGIS) offer a response to the critiques of GIS which were prevalent in the 1990s. It explores aspects of the control and ownership of geographical information, representations of local and indigenous knowledge, scale and scaling up, web-based approaches and some potential future technical and academic directions (Dunn, 2007).

Kyem, (2006) also defined PGIS as a tool that uses GIS to empower under-represented communities. It represents the vision of GIS practitioners interested in the socio-political contribution of GIS to communities. PGIS is the practice of gathering data using traditional methods such as interviews, questions, focus groups, all using some form of paper maps to allow participants to record spatial details. This information is then digitised so that it can be analysed and interrogated using the power of the computer GIS software, and also so that any outputs can then be communicated using computer-drawn map outputs (Laue, 1987).

\section{DEVELOPING PGIS FRAMEWORK FOR LAND CONFLICTS RESOLUTION}

The process used in developing the PGIS model for LCR is summarized in the flow chart in Figure 1. The process begins with the identification of the basic parameters such as existing spatial data, expert and local people's knowledge, and existing management plan. Expert and local knowledge were also obtained from the literature review, field observation, interviews, exploration and analysis. Ephemeral and sketch maps, identification and location of natural and cultural features and monuments, detailing of access roads and additional elements that can contribute to understanding of the conflicts were acknowledged. Hot spots for conflicts were determined with stakeholder identification. At this stage, recommendation(s) can be made on different scenarios towards the resolution of the conflict by stakeholders

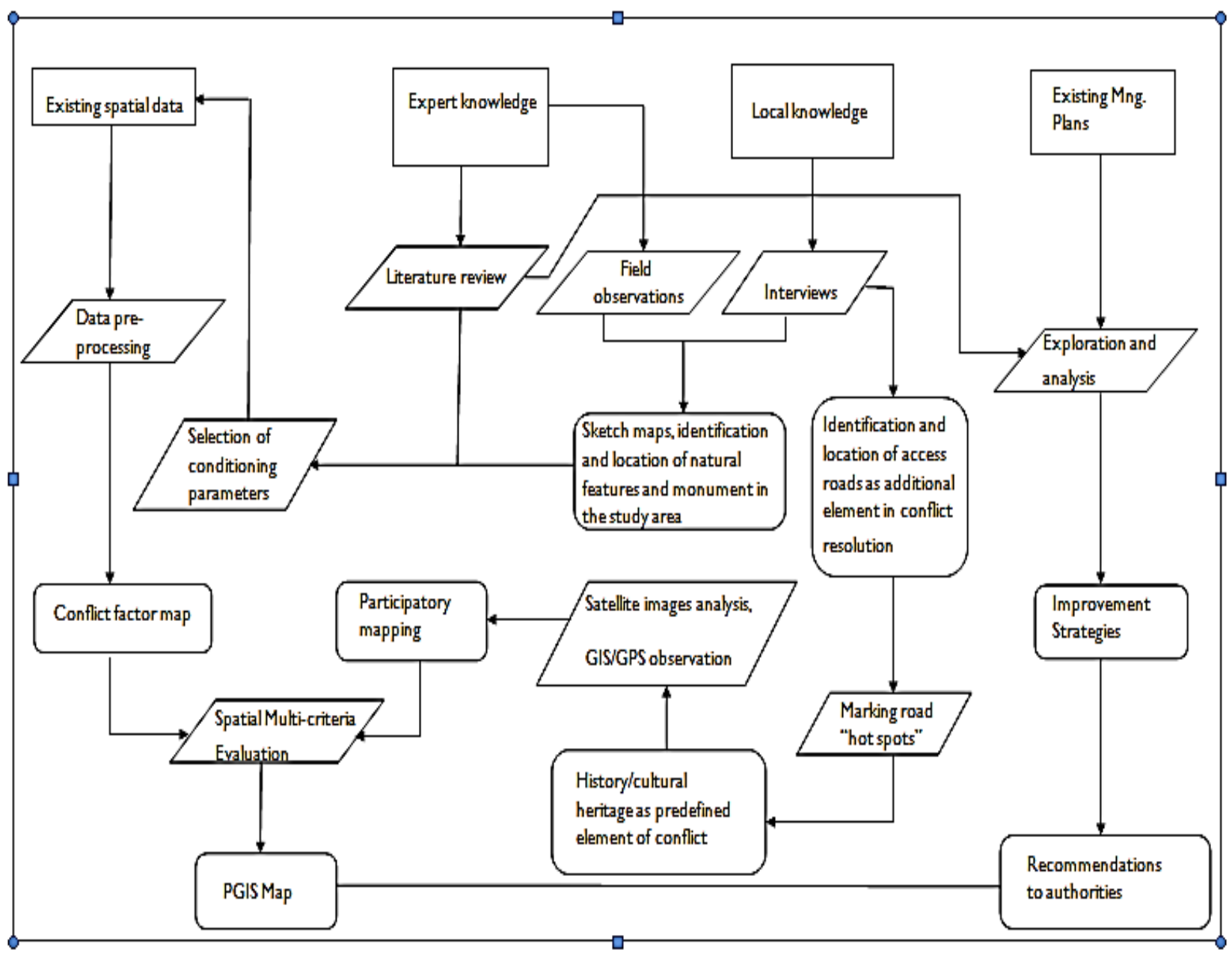

Figure 1. Process for developing a PGIS based framework for land conflict resolution 


\section{FRAMEWORK FOR PGIS CONFLICT RESOLUTION}

The rationale behind any conflict to be resolved is to first examine whether or not the conflict needs to be resolved or should be allowed to take its natural course. This is because conflict is not always negative. Before any conflict is resolved, it is necessary to examine the following key requirement; the nature of that conflict, the circumstances in which it arises, as well as the meaning and justification for its resolution. Other factors that will be considered in using this tool are the actors, their interest (resource in dispute), the stake that each actor has in the resource, the stage (time), and the environment.

\section{Concept of the PGIS framework for Customary Lands Conflict Resolution}

The major aim for the PGIS framework is to establish a satisfactory conflict resolution tool that provides a friendly, accessible, and a pro-poor atmosphere in resolving customary land conflicts. This model seeks to resolve land conflict through a cooperative action that aims at finding win-win solutions and leaves both parties better off with the outcome. Although it may not always be the best option for all the parties, a party in some situation captures the largest share of the benefit through a unilateral action. The PGIS framework creates a participatory based approach of resolving customary land conflicts to meet the characteristics or requirement of a properly resolved conflict where by stakeholders can be put together to form a peaceful consensus building taken into consideration, the social and technical dimension of a particular land conflict.

To achieve this, three key units are considered; the Social Unit (SU), the Technical Unit (TU) and a Decision Making Unit (DMU). This follows the concept of merging social and scientific knowledge to solve a legal problem.

The Social Unit functions as a tool for gathering every relevant non-technical documentary about the conflict which will include; complaints submission by parties, already existing site plans, covenants, receipt, land title search on actor's properties, conflict identification and building of stakeholder consensus. The Technical Units gather and process all geospatial data relevant to the conflict thereby producing a conflict map for conflict visualization. The Decision Making Unit will then be informed by a different alternative scenario in resolving a particular conflict. The above information has been put in Universal Model Language (UML) diagram and presented as Figure 2.

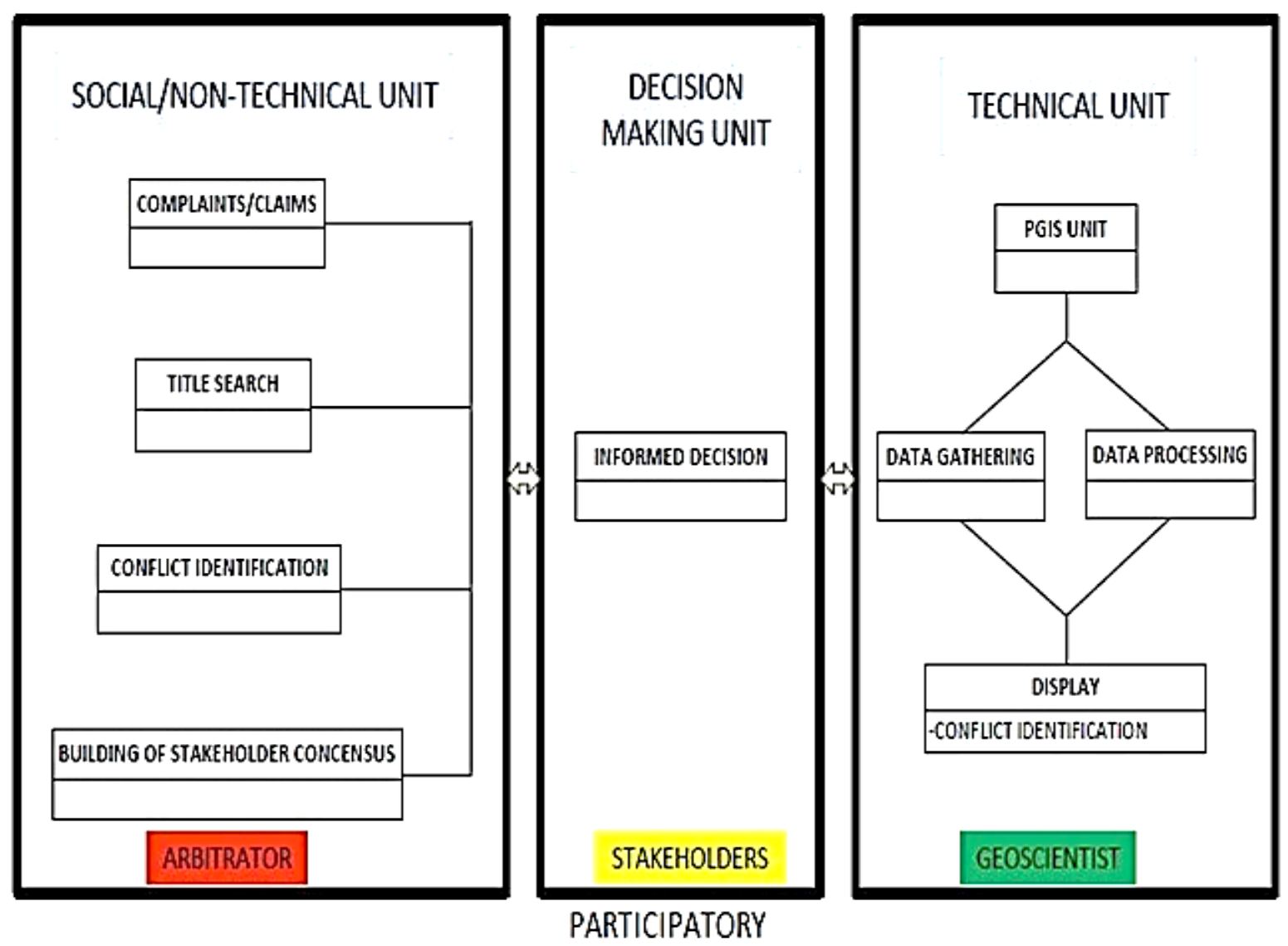

Figure 2. PGIS framework for Land Conflict Resolution 
The nature of this framework can be likened to a butterfly. The social/non-technical and the technical (geospatial) unit serve as the two extreme wings that push or fuel the decision making unit (the body) to create alternative scenarios towards the resolution of a particular conflict. Assumption made is that, it requires both spatial and non-spatial data to gain insight and full understanding of a particular land conflict before it can be resolved satisfactorily.

\subsubsection{The Social or Non-Technical Unit}

The process which is moderated by arbitrator can begin only after a complaint or a claim has been lodged. Any person, or group of persons or institution with one identity, can lodge a complaint. The complainant automatically becomes an actor of the conflict (petitioner). The other party to which the complaints has been lodged against also immediately becomes an actor in that particular conflict (respondent). The actors will then be made to submit their claims and present their cases orally. History and historic evidences of ownership rights are very paramount at this stage. For customary land conflicts, root of ownership title and family tree diagram will be required as well as any evidence to serve as an exhibit. Actors' position, interest, need, value and relationship will be identified. Most evidence and statements made will go through a validation process.

Letter requesting for an official search will be issued to all the actors to be sent to the Lands Commission for a title/deed search. The purpose of the search is to reveal the up-to-date status of the land under dispute. It will then help to identify and appreciate the nature of conflict on the land.

Identification of the existence of a conflict is the next stage where the need for that conflict to be resolved is established. At this stage, stakeholders needed for effective resolutions are identified. Conflict identification comes out with the type, and causes of the conflict and the stage of its escalation. It comes out with the differences in need, interest, values and norms underlying the conflict. Relationships between actors, social dimensions, internal and external influences, as well as periodic stresses are established. In most cases, the identification of the problems starts with some concerns, interrogations, even anxiety or devastation expressed by the community regarding the way their territory is being organized and used.

Having identified stakeholders, the process begins towards peaceful resolution of customary land conflict. Formation of stakeholder group varies from one conflict to another. The formation can be made from a wide range of list depending upon the intensity of the conflict escalation. Stakeholder list include: members of House of Chiefs, Queens, Queen mothers, personnel from the Lands Commission, personnel from Town and Country Planning, district assemblies, the Forestry Commission, opinion leaders in a community, police, private investors and developers.

\subsubsection{The Technical Unit}

The major component in this unit is the Participatory Geographic Information System (PGIS) unit. The PGIS unit also consists of two main sub-components, namely; the data gathering component and the data processing components.
The data gathering components is where technical data relevant to the conflict are participatory gathered. Both spatial and non-spatial data are required. Data are captured by the use of Participatory GIS mapping with community members using tools like GPS, image classification, analysis and visualization. Data needed to be gathered include; actors legal boundaries on the ground, primary and secondary geospatial information which may include current maps, old maps, satellite images, site plans, cognitive maps, sketches etc.

The processing component is where data captured are validated and processed. At every step of the data processing, a feedback procedure will be performed on a regular basis. It allows all partners to validate the process before the practitioners move further. It may be necessary to code some of the variables, especially the qualitative ones. The coding will observe the consistency that will allow for fitting the objectives by setting minimal and maximal values in accordance with a common approach.

\subsubsection{Decision Making Unit}

This unit serves as the judgment unit where informed decisions are proposed to resolve the conflict. The lands Surveyor and the arbitrator in consultation with the stakeholders establish different and alternative scenarios based on which decisions can be taken to resolve the conflict. The DMU combines results from the two units to make effective decisions.

After having integrated all the variables and having validated their respective weighting parameters, the method will allow the formulation of various scenarios under the form of outputs proposing several possible comprehensive land planning maps of the target territories. The stakeholders must be given access to the GIS tool / inputs / outputs / processing in total transparency and respect of the participation procedures (data gathering, variables' weighting, feed backing and validation) so that they will be able to simulate various options for their decision making. The transparency of the procedure is the only guarantee that the participatory approach will be ethically implemented with full respect of social justice within all the compromises that will be discussed.

\subsubsection{Implementation of the PGIS framework}

The success of the implementation of PGIS framework depends on several factors

\section{Ethics of the tool}

Cultural values, and beliefs of a community should be observed during the practice. The underlying principle of this tool should therefore be based on the fact that both parties must view their conflict as a problem to be resolved mutually.

\section{The Don'ts of the Tool}

Actors should be advised not to shy away from the process and also not to avoid or deny the existence of any conflict. Blame games or getting violent should be avoided. External or internal power and manipulations should be diligently prohibited. 


\section{Communication Techniques}

By using effective communication techniques, conflict can be reduced or even prevented. Adjournment of meetings will be made when actors are frustrated, annoyed, and feel so exasperated in such a way that focus is made on individual needs at the expense of others. The following communication technique should be adopted:

Empathy: this is a very important listening technique as it gives the other feedback that he or she is being heard. That is to put yourself in the shoes of the other person, or to see the world through their eyes.

Exploration: probing questions should be asked gently. Each actor must encourage the opposition to talk fully about what is in his or her mind or what he/she is feeling.

Using the "'I" statement: parties should be responsible for their own thoughts rather than attributing motives to other persons. This will decrease the chance of getting offensed by others.

Affirmation: actors should be asked to say positive things about each other even if they are angry with each other. This will show a respectful attitude.

The calming technique: an actor might be angry and may come to a situation with a number of arguments describing how the opponent must be blamed for his or her unhappiness. The goal of the opponent being attacked should be to address the anger of the other assertively. This will be simply done by admitting some fact and truth about the submission being made. In a volatile situation, this might be hard, however, the sign of an individual strength and integrity is the ability to adjourn our immediate reactions in other for a positive goal to be achieved.

\section{Sub-units of the framework}

The sub-units of the tool are as follows: traditional model of public participation and public hearing (e.g. palace or town hall meetings), and citizen panels. The second one is the Analytic-Deliberative model which gives technical information that ensures that broad-based, competent perspectives are treated and also create the opportunity to interactively assign voice to choices about values, alternatives and recommendations. The last but not the least is the Instruments for community based decisions taken which are the GIS and the PGIS. The GIS.

\section{Stakeholder Groups}

Control Groups of about ten (10) should be composed from stakeholders to represent each community in conflict. For the sake of posterity, control group may include men, women and youth. One shared display for the group, and the PGISP. Test group of about seven (7) people should be selected. Group members who are literate on the subject with formal or semi-formal education shall be leaders.

\section{Procedure}

The following steps should be followed: Initial consultation with stakeholders, definition of profile of stakeholders present, data preparation, initial consultation with the community and site analysis, community mapping activity, community validation, technical integration, and presentation and submission

As quoted by Rambaldi, et al., (2002), the path towards community empowerment is paved with interrogations at every step of the process: "Who participates? Who decides on who should participate? Who is left out? Who identifies the problems? Whose problems? Whose questions? Whose perspective? Who establishes the priorities? Who decides on what to visualize and make public? Who controls the use of information? Who is marginalized? Who understands the physical outputs? Who owns the data, the maps and other outputs? Who organizes the regular updating of all the outputs? Who analyzes the spatial information collated? Who has access to the information and why? Who will use it and for what? Ultimately... What has changed? Who benefits from the changes? At what costs? Who is empowered and who is disempowered?"

As recommended by Rambaldi et al., (2002), actors should be advised to strictly adhere to the following guiding principles: openness and honesty, certainty and clarity, obtain informed consent, recognize that they are working with socially differentiated communities and that their presence will never be politically motivated.

They will also be asked to note the following; avoidance of raising false expectations, no rush, avoidance of exposing people to danger. They must be considerate, flexible and make selection of technologies that is adapted to local environment conditions and human capacities. Avoidance of early outlining of boundaries except it is the specific purpose of the exercise should also be adhered to and no activity must be separate.

Actor's readiness to deal with new realities which will emerge from the process and ensuring the understanding of the outputs of the mapping process by all those concerned shall not be over looked. Also ensuring defensive and positive protection of traditional knowledge and indigenous people's rights should be a concern. Informants should be acknowledged and finally, maps and plans should be reviewed.

It is recommended that all actors, without any exception, will reach a clear and deep understanding of the problems and avoid putting pressure on the participatory process of mapping, neither in terms of time, nor in terms of output. Permanently, actors will keep in mind the concerns of ethics. In PGIS practice, the risks of abuse are as high as the potential for development. The key marker of success is the build of interpersonal trust and partnership.

\section{The Role of the Geomatician}

Within PGIS practice, the role of the geomatician is very crucial. Especially, if he/she honestly wants to serve the interests of the community and help them towards effective empowerment, he/she finds himself in the heart of actionresearch. The geomatician has the privilege to utilize his/her professional competence to develop and promote a practice that may truly serve community interests. 
The following two criteria may be highlighted to avoid the lack of respect for the actors, as well as a possible disempowerment of any of them:

i. Appreciable scientific training of each actor for a good practice of PGIS. This can be achieved through the correct use of its technical tools and objective interpretation of its outputs.

ii. The observance of the fundamental ethical rules concerning data ownership, updating and utilization. Guarantee transparency in the communication of the data and of the utilization of the outputs of the PGIS analysis. Contribution of the outputs to people's empowerment will be balanced, specifically by making a clear statement regarding 'who wins' versus 'who loses'.

The geomatician is to take charge of the coordination between all the disciplines. Permanent inter-dialogue with a view of pursuing a consensus and coming out with a common agreement is a major emphasis of the scientist. He or she has the capacity and the responsibility of developing adequate algorithms to process spatial data from various sources in full respect, honest gathering and balanced integration of the perspectives and interests of every actor.

\section{CONCLUDING REMARKS}

A PGIS framework for customary land conflict resolution has been proposed. The framework consist of three separate but interconnected units namely; Technical (spatial) Unit, Non-technical (Social) Unit, and Decision Making Unit.

This framework is novel and can be used to address customary land boundary conflicts. This is because PGIS has the ability to add value to local knowledge in support of spatial analysis. The framework again has the ability of collecting reliable spatial and non-spatial data from local communities, enhance capacity building of indigenes, and increase their learning process. There is a great potential behind the use of PGIS for the purpose of customary land conflict resolution.

This butterfly framework is therefore recommended to be adopted for the resolution of land boundary conflicts in customary areas.

\section{REFERENCES}

Adetula, V. O. A., 2006. "Development, Conflict and Peace Building in Africa", Introduction to Peace and Conflict Studies in West Africa, Gaya, S. B. (ed.), Spectrum Books Ltd., Ibadan. pp. 48-56.

Dunn, C. E., 2007. "Participatory GIS - a people's GIS?" Progress in human geography, 31(5), pp. 616-637.

Kyem, P. A. K., 2006. "Finding Common Grounds in Land Use Conflicts using PGIS: Lessons from Ghana", Participatory Learning and Action, pp. 36 - 40.
Lamptey, F., 2009. "Participatory GIS tools for mapping indigenous knowledge in customary land tenure dynamics; case of peri-urban northern Ghana.” pp. 3-7.

Laue, J., 1987. "The Emergence and Institutionalization of Third Party Roles in Conflict", Conflict Management and Problem Solving: Interpersonal to International Applications, Sandole, D. J. D. and Sandole-Staroste, I. (eds), New York University Press, New York, pp. 17 - 29.

Lund, C., 2003. "Bawku is still volatile: Ethno-political Conflict and State Recognition in Northern Ghana", Journal of Modern African Studies, Vol. 41, No. 4, pp. 587 - 610.

Mandara, C. G., 2007. "Participatory GIS in Mapping Local Context of Conflicts over Pastoral Resources; A Case Study of Duru Haitemba-Babati, Tanzania". MSc Thesis submitted to International Institute for Geo-Information Science and Earth Observation. pp. 90-110.

Margenthan, H., 1973. "Politics among Nations: The struggle for Power and Peace”, $5^{\text {th }}$ edition, McGraw-Hill, Inc., New York, 409 pp.

Pascal P. G., 2003. "PGIS as a Conflict Transformation Tool" pp.1-2.

Rambaldi, G., Banga, S., Tiangco, A., and de-Vera, D., 2002. "Bringing the vertical dimension to the negogiating the table". Preliminary assessment of a conflict resolution case in the philippnes asean biodiversity 2 (1) 17-26.

ARCBC, Los Banos, Philippines. pp. 17-26. Available at http://www.iapad.org/publications/ppgis/Bringing_the_vert ical dimension to the negogiating the table.pdf.

\section{AUTHORS}

Gyamera Ankomah Ebenezer is a Land Surveyor and Geological Engineer by profession with over sixteen years of experience in the field of Geosciences. He is $\mathrm{PhD}$ candidate at the University of Mines and Technology (UMaT), Tarkwa, Ghana- West Africa, Chartered Project Manager, fellow at American Academy of Project Management (FAAPM) and a member of Ghana Institution of Surveyors (MGhIS)

Dr. Anthony Arko-Adei is a Senior Lecturer at the Kwame Nkrumah University of Science and Technology and expert in Land administration with over twenty years of experience. $\mathrm{He}$ is a member of Ghana Institution of Engineers (GIE), Ghana Institution of Surveyors (MGhIS) and a Licensed Surveyor.

Dr. Edward Eric Duncan is a senior Lecturer at UMaT with over thirteen years of experience in teaching and research. He has over thirty publications to his credit in the areas of GIS (2D \& 3D), Remote sensing, and Geomatic Education. $\mathrm{He}$ is a member of Ghana Institution of Surveyors (MGhIS)

J. S. Y. Kuma is a full professor and a Vice Chancellor in UMaT with over thirty years of experience. He is a fellow at African Scientific Institute (FASI), Member of Ghana Institution of Engineers (MGhIE), Member of Ghana Institution of Geoscientist and Members of International Association of Hydrologist. 